\title{
Economia Solidária como estratégia de desenvolvimento territorial: o caso do Baixo Tocantins, com ênfase na experimentação de Igarapé-Miri/Pará
}

\section{Solidaryt Economy as a strategy of territorial development: the case of Igarapé-Miri, Territory low Tocantins/Pará}

Isaac Fonseca Araíjo - Educador. Licenciado em Letras (UEPA/CCSE). Especialista em Letramento e Formação de Professores (UEPA/CCSE) e em Gestão Pública e Sociedade (UFT). Mestrando em Ciências Sociais/Sociologia (UFPA/IFCH), Belém-PA. E-mail: isaac.educador@hotmail.com

Armando Lirio de Souz̃ - Economista, professor adjunto da Faculdade de Ciências Econômicas do Instituto de Ciências Sociais Aplicadas da Universidade Federal do Pará (ICSA-UFPA) e doutor em Desenvolvimento Rural, Belém-PA. E-mail: armandolirio@gmail.com

\section{Resumo}

Este texto analisa a trajetória da Economia Solidária no município de Igarapé-Miri (PA). O recorte analítico busca evidenciar a experimentação de "outra economia" no Território da Cidadania do Baixo Tocantins, enquanto estratégia de gestão e desenvolvimento territorial. $O$ presente trabalho está estruturado em dois eixos analíticos: (i) a experimentação de outra economia enquanto movimento de sociedade civil organizada, por um lado, e (ii) o fomento a esse "modelo" alternativo de socioeconomia como política governamental, por outro. Em suma, compreendem-se os resultados desse processo político de organização dos trabalhadores no campo do desenvolvimento como um continuum de transitoriedades, cuja construção tem elevado a economia solidária do grau de experiência comunitária ao estágio de política pública municipal.

\section{Palavras-chave}

Economia Solidária. Política Pública. Desenvolvimento Territorial.

\begin{abstract}
This text analyzes the path of the solidary economy in the municipal district of IgarapéMiri (PA). The analytic cutting to understand the experimentation of another economy in the Sitzenship Territory of Low Tocantins, while administration strategy and territorial development. The present work is structured in two analytic axes: (i) the experimentation of another economy while movement of organized civil society, by one side, and (ii) the fomentation to that "alternative model" of social-economic as government politics, for other. In highest, the results of that political process of the workers' organization are understood in the field of the development as a continue way of transitoriness, whose construction has been elevating the solidary economy of the degree of community experience to the apprenticeship of public politics.
\end{abstract}

\section{Keywords}

Solidary Economy. Public Politics. Territorial Development. 


\section{INTRODUÇÃO}

Segundo Paul Singer (2002), é a partir do associativismo e do cooperativismo que a economia solidária explica sua origem na realidade brasileira. Anteriormente, o próprio Singer (2000) afirmava que a cooperativa de produção seria a unidade típica da economia solidária ou mesmo seria a emergência de um novo modo de produção. Ou seja, nos últimos anos ampliou-se bastante o significado da economia solidária e novas interpretações atualizaram a temática, enquanto campo de pesquisa, assim como o sentido de suas representações socioprodutivas e seu "poliformismo institucional". Isso fortaleceu a tese de uma nova "forma social de produção” (GAIGER, 2003; GAIGER, 2004). No contexto amazônico, em particular, esse argumento se sustenta especialmente depois da primeira metade da década de 1980, época em que "surgiram em diversos espaços dessa região experiências de 'revendão', ‘cantinão', ‘caixa agrícola', etc.”, como um "ressurgimento das organizações" econômicas coletivas - nessa conjuntura "para compra e venda de produtos" (ARAÚJO, 2003, p. 10). Um movimento, portanto, originário no mundo do trabalho rural, sobretudo nas atividades do extrativismo vegetal, na agricultura familiar e na pesca artesanal. Esse fenômeno associativista/cooperativista na Amazônia, com particular efeito no Pará, foi fortemente influenciado pela ação pastoral da igreja católica e de diversos movimentos sociais (SOUSA, 2000).

Em tese, esses fenômenos, sob a liderança dos sindicatos dos trabalhadores rurais, foram projetados como instrumentos alternativos, na vivência do trabalho associado com fundamento na solidariedade e cooperação (SOUZA, 2011). Nesse sentido, havia o objetivo de experimentar outra economia e outra sociedade decorrentes de uma "[...] criação em processo contínuo de trabalhadores em luta contra o capitalismo" (SINGER, 2000, p. 13), um movimento político em contraposição ao autoritarismo e ao patrimonialismo, portanto, em essência plural, democrático e igualitário. Por isso, estrategicamente, assume-se um discurso ideológico enquanto caminho de libertação dos trabalhadores, cuja materialidade ancora-se em projetos orgânicos relativos à defesa/garantia de direitos, autonomia e emancipação (ARAÚJO, 2003). No entanto, à medida que essa temática de pesquisa assume relevância na academia, há o desafio e a tentativa de "[...] produzir uma teoria da prática atual e real das classes subalternas" (GAIGER, 2003, p. 184), ou melhor, interpretar as práticas associativistas e de autogestão contemporâneas dos trabalhadores urbanos e rurais.

No primeiro momento, essa ação política do movimento social do campo permitiu que o comando das organizações sindicais passasse a ser exercido pelos

Novos Cadernos NAEA, v. 16, n. 1, Suplemento, p. 43-67, jun. 2013 
legítimos representantes dos trabalhadores rurais. Paulatinamente, isso possibilitou iniciar a desestruturação do domínio dos agentes políticos vinculados ao poder governamental e as oligarquias locais, portanto, impedir o uso das organizações sindicais como aparelho de manipulação. Em um segundo momento, representou o principal instrumento organizacional para que o movimento ${ }^{1}$ colocasse em sua agenda programática o debate econômico.

Nos anos de 1970 e 1980, essa conjuntura de luta política contra o regime autoritário na região amazônica influenciou decisivamente a formação sócio-espacial do Território da Cidadania do Baixo Tocantins. Por isso, este território tem em seu histórico importantes processos econômicos pautados na experimentação de um diferente mundo do trabalho, na perspectiva de construção de outro desenvolvimento. Com base no que se tem investigado, observa-se a consolidação de práticas de economia solidária, concebidas e vivenciadas pela adoção de princípios de democracia, autogestão, emancipação e sustentabilidade enquanto orientadores de suas relações econômicas e socioambientais. Ao que parece, tem-se aqui um fenômeno histórico de constituição de associação livre e voluntária entre trabalhadores, cuja materialização ocorreu de múltiplas maneiras: desde mutirões para troca de serviços (em limpeza de áreas agrícolas, por exemplo), cantinas e/ou caixas comunitárias, até a organização de empreendimentos econômicos solidários, cooperativas agroindustriais ou, ainda, centrais de cooperativas (ARAÚJO; SOUZA, 2012).

Nessa perspectiva supõe-se que o município de Igarapé-Miri, em grande medida, segue a trajetória do seu território - o Baixo Tocantins -, enquanto movimento de resistência dos trabalhadores livremente associados em contraposição à subordinação e/ou alienação do trabalho ao capital (BENINI et al., 2012). Desta maneira, essa realidade pressupõe que as experiências associativistas e de autogestão entre trabalhadores do campo testemunham a vivência de um processo de desenvolvimento territorial que busca construir elementos para uma nova sociabilidade. Por fim, decorridas mais de duas décadas dessas experimentações, houve nos últimos quatro anos a iniciativa de introduzir a economia solidária e o cooperativismo na agenda do governo municipal de Igarapé-Miri, enquanto estratégia de fomento ao desenvolvimento. Em certo sentido, criaram-se as bases de estimulo à organização do trabalho coletivo e solidário no território miriense.

\footnotetext{
Cabe sublinhar que, por um longo tempo, o sindicalismo na Amazônia, os fragmentos de atuação pastoral católica e os movimentos sociais ocuparam-se, quase exclusivamente, com a formação política de seus militantes, tendo em vista a organização social das categorias para a luta em defesa dos direitos coletivos. Somente em um segundo momento, as lideranças regionais reconheceram que a mobilização classista tinha limites, quando não articulada a outras questões de ordem estratégica. Portanto, era preciso discutir o bem-viver também economicamente.
}

Novos Cadernos NAEA, v. 16, n. 1, Suplemento, p. 43-67, jun. 2013 
O texto que segue, constitui-se numa análise-síntese da trajetória da economia solidária enquanto estratégia de desenvolvimento territorial. Faz-se opção por uma concepção metodológica que considera tal trajetória como um continuum de transitoriedades ${ }^{2}$, pressupondo-se que o Território da Cidadania do Baixo Tocantins acumula experiências significativas de economia solidária: a priori, como vivência comunitária no campo da produção e do consumo; em seguida, a partir de organizações associativistas e cooperativistas mobilizadas pelo movimento sindical; a posteriori, com o fenômeno dos empreendimentos econômicos solidários e entidades de apoio e, finalmente, na recente formatação embrionária de políticas públicas de economia solidária.

\section{ECONOMIA SOLIDÁRIA, TERRITÓRIO E DESENVOLVIMENTO}

Conforme argumenta Singer (2002, p. 114), a economia solidária "foi concebida para ser uma alternativa superior [ao capitalismo], por proporcionar às pessoas que a adotam, enquanto produtoras, poupadoras, consumidoras etc. uma vida melhor"

Uma vida melhor não apenas no sentido de que possam consumir mais com menos dispêndio de esforço produtivo, mas também melhor no relacionamento com familiares, amigos, vizinhos, colegas de trabalho, colegas de estudo etc.; na liberdade de cada um de escolher o trabalho que lhe dá mais satisfação; no direito à autonomia na atividade produtiva, de não ter de se submeter a ordens alheias, de participar plenamente das decisões que o afetam (SINGER, 2002, p. 114-115).

Essa assertiva, entretanto, não é suficiente para satisfazer um conjunto de inquietações. Afinal, o que é ser "superior ao capitalismo"? De qual "alternativa superior" está se falando? A esse respeito, Souza (2012, p. 2) questiona-se ao indagar: "o que é Economia Solidária? Trata-se de uma ação comunitária/ associativista e atitudes de filantropia e caridade? Pode ser apresentada como uma estratégia de arranjos sócio-produtivos locais ou uma forma diferente de

\footnotetext{
Os resultados deste trabalho confirmam que os aspectos transitórios e experimentais são (ainda) as principais características constituintes da economia solidária. A trajetória do Baixo Tocantins, entendida à luz da experiência de Igarapé-Miri, parece testemunhar satisfatoriamente esse fenômeno. As constatações a que se tem chegado sobre a construção desse território sinalizam que a experimentação dessa outra economia, concebida e processada como fundamentos de um sistema socioeconômico alternativo ao capitalismo, constitui (em função dos aspectos anteriormente citados) um continuum (sucessão de fatos históricos vinculados pela natureza e desdobramentos) de vivências associativas no mundo do trabalho. Essa realidade histórica explica a carência de substância epistemológica no campo da economia solidária, necessária à formação de uma matriz científica suficiente para "definir" e/o "explicar" essa "outra economia possível", do ponto de vista de sua condição de fenômeno universal.
}

Novos Cadernos NAEA, v. 16, n. 1, Suplemento, p. 43-67, jun. 2013 
fazer a economia e o desenvolvimento?" Conforme lembra o autor supracitado: "há discussões teóricas que vinculam a origem da economia solidária aos princípios do socialismo utópico e outras que a conceituam como um fenômeno novo, decorrente do processo de desestruturação do mundo do trabalho" (SOUZA, 2012, p. 2). Majoritariamente, essas reflexões têm como referencial a crise da sociedade industrial e a identificação de experiências autogestionárias (SOUZA, 2012).

Esse enquadramento de análise, em certo sentido, compromete tais reflexões, pois parece desconsiderar elementos fundamentais do universo orgânico da solidariedade, passíveis de exemplificação nas práticas comunitárias presentes em "sociedades não industriais". Além disso, é de proveito destacar que a economia solidária ultrapassa o limite do cálculo meramente econômico, possuindo estreita relação com a cultura das comunidades que a vivenciam. Para Souza (2012) é preciso pensar no sentido da economia solidária com base em um "patamar superior de análise", que avance na "identificação de redes de desenvolvimento territorial solidário" (ORTEGA, 2007 apud SOUZA, 2012, p. 3), considerando-se o conjunto de suas dimensões culturais, socioeconômicas e ambientais.

O pressuposto de valorizar a análise da dinâmica das redes de desenvolvimento territorial solidário converge ao interesse em investigar as experiências da economia solidária no Território da Cidadania do Baixo Tocantins, em particular no município de Igarapé-Miri. Em certa medida, o surgimento da economia solidária na região gesta um novo conceito e uma prática igualmente nova de desenvolvimento, cuja formatação supera tradicionais paradigmas relativos ao tema, normalmente vinculados a ideia de progresso, modernização ou crescimento econômico. Em rejeição aos citados e tradicionais paradigmas, essa concepção alternativa estabelece como premissa um desenvolvimento de bases socialmente justas, viáveis do ponto de vista econômico, sustentáveis sob o viés ecológico e aceitáveis culturalmente (ALMEIDA, 1997). Evidentemente, propor bases capazes de incorporar em suas matrizes socioprodutivas novas tecnologias e de se autoaprimorarem tecnicamente, não se abstendo ao usufruto e/ou à afirmação de tradições e valores que lhe sejam peculiares. Para tornar materialidade esse (novo) processo de desenvolvimento, tornou-se um imperativo rejeitar os valores capitalistas da competição, do individualismo, da depredação ambiental e da exclusão, para incorporar, equivalentemente, a cooperação, solidariedade, sustentabilidade e a inclusão social como fundamentos de uma nova territorialidade e ruralidade, elementos resultantes de uma construção histórica (WANDERLEY, 2009).

Novos Cadernos NAEA, v. 16, n. 1, Suplemento, p. 43-67, jun. 2013 
Sabe-se que a expressão do desenvolvimento territorial com base na economia solidária, acima conceituada, tem origem no campo, sob natureza de movimento: um tecido sociopolítico resultante da articulação de um conjunto de sujeitos da sociedade civil. A configuração dessa plataforma de desenvolvimento territorial tem permitido, na trajetória do Baixo Tocantins, a formação de um capital social, com a quebra "de um dos mitos fundadores da civilização moderna: o de que a sociedade é 'um conjunto de indivíduos independentes, cada um agindo para alcançar objetivos a que chegariam independentemente uns dos outros" (COLEMAN, 1990 apud ABRAMOVAY, 2000, p. 4). O capital social "permite ver que os indivíduos não agem independentemente, que seus objetivos não são estabelecidos de maneira isolada nem estritamente egoísta" (idem). Isso permite ver as "estruturas sociais como recursos, como um ativo de capital de que os indivíduos podem dispor", conforme as necessidades e os interesses coletivos. Para Coleman (1990), citado por Abramovay (2000),

O capital social não é uma entidade singular, mas uma variedade de diferentes entidades que possuem duas características em comum: consistem em algum aspecto de uma estrutura social e facilitam algumas ações dos indivíduos que estão no interior desta estrutura'. O capital social, neste sentido, é produtivo, já que ele torna possível que se alcance objetivos que não seriam atingidos na sua ausência (COLEMAN, 1990, p. 302 apud ABRAMOVAY, 2000, p. 4).

Fundamentado em Coleman (1990) e Putnam (1993/1996), Corrêa (2010) lembra que "capital social é a característica da organização social", e tem haver com "confiança, normas e sistemas que contribuem para aumentar a eficiência da sociedade”. É “como um bem público", na medida em que se torna articulação integradora de forças produtivas, pacto social. Do ponto de vista epistemológico, a formação do capital social - entendido enquanto um dinamizador do território - explica-se (entre outros elementos) pela existência do que Fligstein (2007, p. 61) denomina de "habilidades sociais", assim, "a idéia de habilidade social é que os atores precisam induzir a cooperação dos outros. A habilidade de motivar os outros a tomar parte em uma ação coletiva é uma habilidade social que se prova crucial para a construção e reprodução de ordens sociais locais" (FLIGSTEIN, 2007, p. 62).

Essa concepção de desenvolvimento pressupõe uma situcionalidade de território, uma territorialidade, cujo valor identitário constitui "uma organização complexa feita por laços que vão muito além de seus atributos naturais" - "um tecido social" (ABRAMOVAY, 2000; WANDELEY, 2009). Para Abramovay (2000, p. 07), "um território representa uma trama de relações com raízes históricas, configurações políticas e identidades".

Novos Cadernos NAEA, v. 16, n. 1, Suplemento, p. 43-67, jun. 2013 
No âmbito deste trabalho, a noção de território é também assumida como ação política (PERICO, 2009) materializada de um conjunto de instituições públicas e privadas; instrumentos representativos orgânicos e/ou operacionais; arranjos sociais, políticos, econômicos e culturais e o espaço que constituem uma dada região. Não se trata de uma "soma das partes", mas do conjunto que integra os seus diferentes e diversos elementos. Assim, a noção de território ultrapassa o aspecto da geografia regional para se efetivar nas afinidades histórico-culturais, socioeconômicas e geopolíticas, entre outras, que interligam seus diferentes sujeitos mediados por relações de poder. Desse ponto de vista, a territorialidade significa a unidade (pactuação) promovida pela integração dos múltiplos atores constituintes do território. Unidade que, embora permita divergências, conflitos, disputas e até rompimentos, mantém-se por representar um esforço coletivo para consolidação de projetos estratégicos de desenvolvimento. "A territorialidade conforma-se nas estratégias espaciais para o exercício da ocupação/apropriação, do empoderamento e da regulação/controle do território" (PERICO, 2009, p. 62). Em outros termos, traduz-se na maneira como os grupos se organizam para fazer a gestão, defender ou integrar seu território, constituindo expressão política de identidade (PERICO; RIBERO, 2005).

A abordagem territorial do desenvolvimento, entretanto, para além de sua importância, deve ser testada no que diz respeito à aplicabilidade, já que a construção de um território é sempre marcada por contradições, conflitos e limites históricos, sem desconsiderar suas potencialidades de naturezas diversas. Nesse sentido, a argumentação de Corrêa (2010) é propícia à discussão do desenvolvimento territorial como fenômeno situado (o território como locus onde a vida social acontece). Suas considerações enfatizam que

O desenvolvimento de uma economia é sempre promovido por atores de uma sociedade que tem uma cultura, formas e mecanismos próprios de organização. Cada sociedade encoraja o surgimento de formas específicas de organização e de instituições que lhe são próprias e que haverão de favorecer ou dificultar a atividade econômica, pelo fato de os agentes econômicos tomarem suas decisões nesse entorno organizacional e institucional e por, evidentemente, nem sempre seguirem as prescrições teóricas dos modelos econômicos (CORRÊA, 2010, p. 23).

A construção de um território, sob a perspectiva do desenvolvimento, demanda a viabilização articulada de um conjunto de elementos estruturantes e conjunturais complexos: exige que os sujeitos sociais se reconheçam e sejam reconhecidos como tais; recomenda que as bases conceituais, técnicas e tecnológicas do desenvolvimento e os instrumentos a ele necessários sejam 
por esses sujeitos apropriados; indica, como imprescindíveis, o reconhecimento e a valoração das identidades locais e sugere a formação de redes ${ }^{3}$ e/ou arranjos institucionais de colaboração socioprodutiva como combustível da territorialidade. À luz desse contexto, o fortalecimento da economia solidária tornou-se, na realidade ora debatida, uma substância estratégica, tendo em vista a sua capacidade de fomento ao desenvolvimento territorial.

\section{O TERRITÓRIO DO BAIXO TOCANTINS/PA: CONFIGURAÇÃO E DINÂMICA}

O aspecto multidimensional talvez seja a principal característica do Território da Cidadania do Baixo Tocantins ${ }^{4}$, cuja dinâmica possui elevado grau de complexidade (SOUZA; FILIPPI, 2008). Segundo Souza (2011, p. 1), as "transformações socioespaciais" ocorridas nesse território, especialmente "a partir da década de 1980", "são representativas do padrão de desenvolvimento capitalista introduzido na Amazônia por meio da instalação de grandes projetos

3 A concepção de rede (ou arranjo) remete à ideia de "tecido", o que se obtém a partir de uma "costura". Tecnicamente, uma costura é resultante do entrelaçamento de vários fios, que se integram indissociavelmente por muitos nós a formar uma estrutura (peça) de perfeita harmonia. Nesse tecido inexiste hierarquização, verticalidade, uma vez que sua constituição é toda horizontal; não há um nó mais importante do que outro. A rigor, se um deles for desatado, toda a rede será afetada, tanto na forma quanto na função. Sob essa lógica, rede torna-se sinônimo de plataforma (como na rede de dormir: lugar para se repousar, amparo para as pessoas), à medida que, ao se constituir num conjunto de sujeitos, instrumentos e esforços programaticamente integrados, favorece e/ou subsidia processos de desenvolvimento. No campo da economia solidária, o trabalho organizado por Mance (2003) traz bons exemplos de experiências de desenvolvimento em rede.

4 Segundo Souza (2011), há diferentes definições para o Baixo Tocantins. A primeira, sintetizada no nome tradicional de Baixo Tocantins, foi assumida (entre 1970 e 1980) pelo movimento sindical rural e um conjunto de outros movimentos sociais, entre eles o dos profissionais da educação. Faziam parte desse território: Abaetetuba, Baião, Bagre, Cametá, Igarapé-Miri, Oeiras do Pará, Mocajuba, Moju e Limoeiro do Ajuru, articulados por convergências políticas, socioculturais e econômicas. A partir de 2000, o território passou a ser compreendido por esses movimentos como região do Baixo Tocantins, somando-se aos municípios citados o de Barcarena. Para o IBGE, esse espaço constitui uma parte da Mesorregião Nordeste do Pará, constituída pelas Microrregiões de Cametá (Abaetetuba, Baião, Cametá, Igarapé-Miri, Oeiras do Pará, Limoeiro do Ajuru e Mocajuba) e de Tomé-Açu (Acará, Moju, Tailândia e ToméAçu). Com a implantação do Programa Territórios da Cidadania, pelo Governo Federal, a região passou a ser chamada, nesse contexto, de Território da Cidadania do Baixo Tocantins, composta pelos municípios de Abaetetuba, Acará, Baião, Barcarena, Cametá, Igarapé-Miri, Oeiras do Pará, Limoeiro do Ajuru, Mocajuba, Moju e Tailândia. Na estruturação definida pelo Governo do Estado do Pará, o Baixo Tocantins constitui-se como uma das 12 Regiões de Integração (RI) do Estado, constituída pelos mesmos 11 municípios componentes do território da cidadania anteriormente citado. Neste trabalho, utiliza-se como referencial o conceito de Território da Cidadania, dadas às interfaces ora produzidas entre os temas economia solidária e desenvolvimento territorial, oportunizado pelo Colegiado de Desenvolvimento Territorial e pelo Fórum Territorial de Economia Solidária, ambos do Baixo Tocantins.

Novos Cadernos NAEA, v. 16, n. 1, Suplemento, p. 43-67, jun. 2013 
econômicos e de infraestrutura". Inclinado em compreender a divisão territorial do trabalho no Baixo Tocantins, Souza (2011) utiliza-se da categoria de subterritórios, enquanto tipologia de análise, para apontar a existência de pelo menos três subterritórios, "com graus diferenciados de integração e articulação", coexistindo na dinâmica dessa região, conforme expõe a Figura 1.

Figura 1: Mapa de Uso do Território da Cidadania do Baixo Tocantins (PA), 2011.

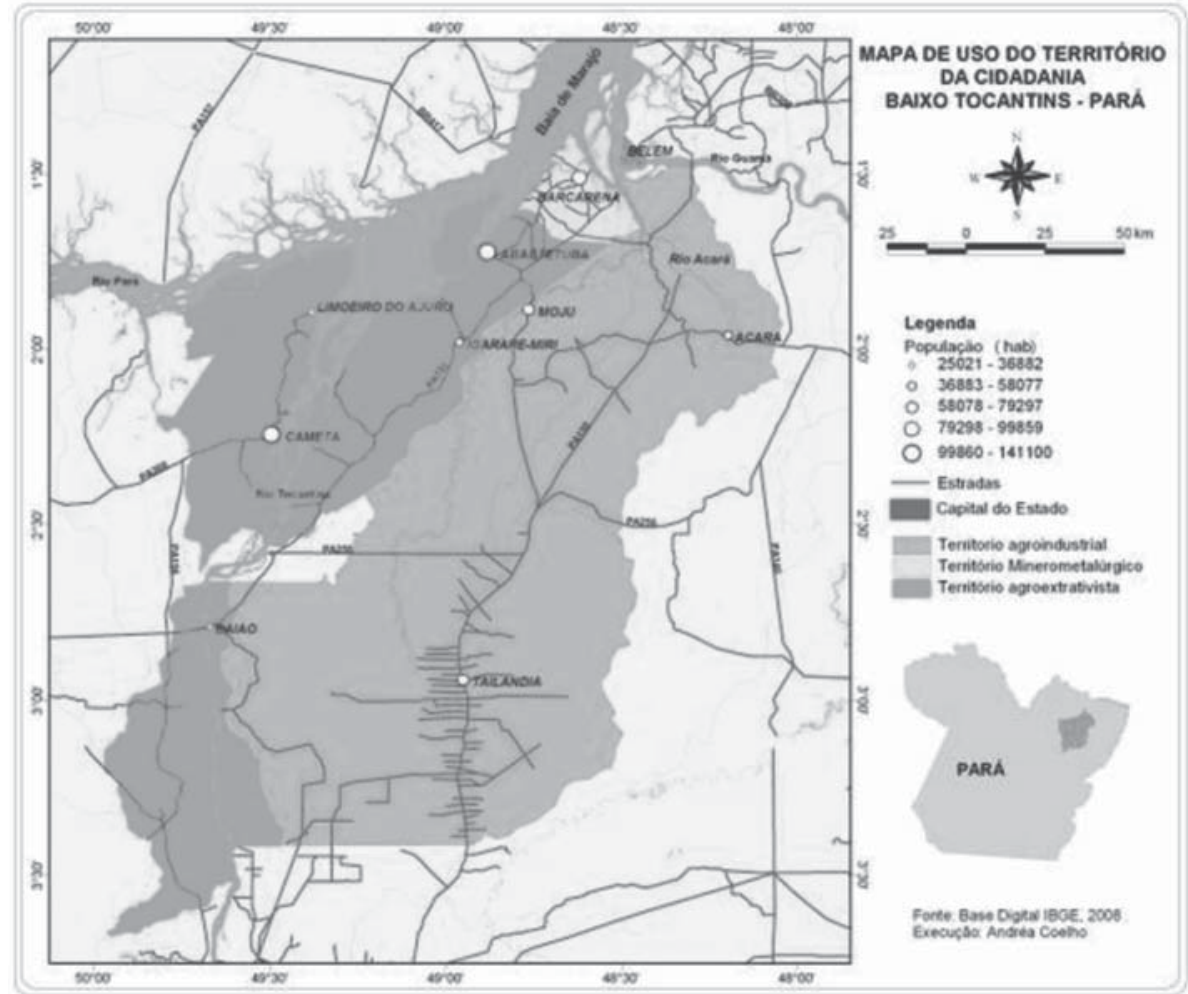

Fonte: Souza (2011).

Em tom verde no mapa, o subterritório agroextrativista denota "predomínio das áreas de várzeas com forte presença da agricultura familiar", o que sugere um "menor nível de concentração da terra e menores taxas de desmatamento", pela combinação de práticas de "monocultura do açaí e sistemas agroflorestais", entre outros arranjos. Nesta linha sobressaem-se os municípios de Abaetetuba, Igarapé-Miri, Cametá, Limoeiro do Ajuru, Oeiras do Pará e Mocajuba. A tonalidade laranja caracteriza no mapa o subterritório dos projetos agroindustriais "pelo avanço da monocultura do dendê (agroenergia) e do coco-da-baía, com sistemas de integração da agricultura familiar, concentração de terras, elevado 
nível de desmatamento e conflitos socioambientais". Possuem forte presença nessa conjuntura os municípios de Acará, Moju e Tailândia. Por fim, o subterritório minero-metalúrgico, caracterizado pelo tom amarelo, "praticamente concentrase no município de Barcarena", tendo como símbolo o complexo ALBRAS/ ALUNORTE (SOUZA, 2011, p. 3-4).

Os estudos desse autor, entretanto, apontam que ao lado das divergências de perspectivas e contradições de trajetórias relativas aos subterritorios acima configurados há um conjunto de características comuns entre eles, embora majoritariamente negativas, do ponto de vista desta argumentação:

No âmbito da produção agrícola e extrativista vegetal há grande participação da agricultura familiar; no campo dos indicadores sociais e ambientais, a precariedade e fragilidade dos serviços públicos; no campo econômico, a visão voltada para a exportação, por isso, tanto os grandes empreendimentos econômicos como a unidade produtiva familiar estão integrados à acumulação ampliada de capital, particularmente aos processos contemporâneos de financeirização (SOUZA, 2011, p. 4).

A convivência entre expressões de homogeneidade e heterogeneidade, de fato, constitui uma das marcas históricas do Baixo Tocantins, pois, trata-se de uma das áreas mais antigas de ocupação da Amazônia brasileira pela colonização portuguesa, mas que ainda convive com alto índice de concentração de renda e desigualdades sociais. Isso se explica, por exemplo, pelo fato de apenas um dentre seus onze municípios - o de Barcarena - atualmente deter 60\% do Produto Interno Bruto (PIB) gerado na região (SOUZA, 2011, p. 6). Esse histórico cenário favorece o estabelecimento de uma conjuntura de contradições e limites estruturais e, em decorrência destes, a formação de conflitos e/ou disputas de muitas ordens com flutuações no tecido sociopolítico do território.

Por outro lado, um valor estratégico do Baixo Tocantins diz respeito ao seu "caráter rural com potencial para implantação de projetos econômicos e sociais voltados para a agricultura familiar" (SOUZA, 2011, p. 6). No universo do rural enquanto expressão do território, a estrutura fundiária da região apresentase como um relevante indicador, em função de sua distribuição assentar-se predominantemente na unidade familiar. Dados do Censo Agropecuário de 2006, sistematizados por Sousa (2011), dão conta de que do total de estabelecimentos rurais do território, $92,47 \%$ estão definidos como unidades familiares, embora ocupem (apenas) 52,85\% da área total.

No que tange à distribuição da área total, verifica-se que entre os estabelecimentos da agricultura familiar a média é de 20,4 hectares por unidade 
produtiva, ao passo que no universo da agricultura não familiar esse índice é de 223,4 hectares por unidade (SOUZA, 2011; BRASIL, 2006). A importância da agricultura familiar no processo de desenvolvimento do Baixo Tocantins pode ser medida também na ocupação da força de trabalho. Ainda com base nas informações do IBGE (BRASIL, 2006), nota-se que do total de trabalhadores do setor agropecuário 84\% estão ocupados em estabelecimentos familiares.

$\mathrm{Na}$ linha do que aqui se tem entendido/sistematizado como configuração socioeconômica, as contribuições do Plano Territorial de Desenvolvimento Rural Sustentável do Baixo Tocantins (PTDRS) também indicam a forte presença de conflitos e contradições enquanto fenômenos que historicamente têm influenciado a dinâmica de vida nesse território. Segundo o PTDRS encontramse entre tais fenômenos a "luta pela terra, pelo acesso ao crédito, à assistência técnica para a produção, melhoria de infraestruturas e garantia de serviços sociais". Entretanto, se por um lado essa dinamização territorial tem contribuído para a instalação de um cenário negativo de convivência regional, por outro, tem induzido a promoção e/ou fortalecimento de um conjunto diversificado de "organizações, instituições sociais e movimentos reivindicatórios" (BRASIL, 2011, p. 19).

Com relação à estrutura socioprodutiva, afirma o PTDRS que a "produção pecuária, o extrativismo vegetal, a produção agrícola temporária, os projetos de assentamento e a pesca" (atualmente) "dão o tom à dinâmica" do território, no que concerne a atividades econômicas. Essa realidade reforça a compreensão de que o processo de desenvolvimento do Baixo Tocantins (em grau elevado) guarda estreita relação com a ocupação/uso da terra.

Tais registros sobre a estrutura fundiária do Baixo Tocantins são relevantes do ponto de vista do que se propõe discutir neste trabalho, notadamente porque expressam a dinâmica contemporânea de uso da propriedade no território. Embora a unidade produtiva familiar seja privada sabe-se que seu uso tem se mostrado passível de funcionamento coletivo, quando pertencente a estratégias associativistas e/ou comunitárias (fenômenos muito presentes na Amazônia) ou integrado a empreendimentos econômicos solidários (EES).

Em um plano macro de análise, esse processo histórico-conjuntural configura dois padrões de desenvolvimento: de um lado, aquele pautado em grandes projetos ${ }^{5}$, marcado por elevados indicadores de concentração de renda,

\footnotetext{
Destaquem-se aqui o complexo ALBRAS/ALUNORTE, uma perene demonstração do vigor do capital, as fortes e negativas influências da Usina Hidrelétrica de Tucuruí na região e os grandes projetos agroindustriais incentivadores da monocultura enquanto padrão produtivo e da concentração de propriedade, atualmente com grande prioridade para a cultura do dendê com o objetivo de criar insumos para os projetos de agroenergia.
}

Novos Cadernos NAEA, v. 16, n. 1, Suplemento, p. 43-67, jun. 2013 
desigualdades socioeconômicas, conflitos ambientais e preconceitos étnicoculturais e, de outro, um desenvolvimento (pouco contabilizado) que se evidencia/ cristaliza especialmente pela dinâmica da agricultura familiar, da pesca e dos pequenos e médios empreendimentos econômicos e que, igualmente, afirma-se nos saberes e valores das comunidades tradicionais e na economia da cultura.

O paradoxo histórico que configura e dinamiza o Território da Cidadania do Baixo Tocantins tem se tornado uma conjuntura fértil para o surgimento de alternativas à desestruturação das bases produtivas tradicionais do território (SOUZA, 2011), fenômeno largamente influenciado pela instalação de grandes projetos na região. Alternativas materializadas na forma de processos organizativos (mais definidos a partir de 1980) intraterritoriais, notadamente alimentados pelo perfil associativista/comunitário inerente ao território. Segundo esse autor, tais processos identificam-se como:

Elementos de renovação e resistência ou pistas de um padrão de desenvolvimento capaz de orientar para a superação do viés concentrador de renda e de desigualdades regionais. Observa-se que a superação das décadas do patronato (1950-1980) e o avanço da produção agroextrativista do açaí (1990-2000) geraram um novo quadro nas relações políticas, econômicas e sociais no Baixo Tocantins (SOUZA, 2011, p. 4).

Enquanto ideário e intervenção, simultaneamente, esses processos organizativos confirmam o protagonismo de diferentes e diversos sujeitos sociais na construção de uma matriz de desenvolvimento alternativa ao capitalismo. Tem-se, pois, uma matriz com fundamento nos princípios e valores da economia solidária. Acredita-se que essa estrutura orgânica de resistência ao capital tem se caracterizado por um conjunto de experimentações territoriais, entre as quais a trajetória do município de Igarapé-Miri se apresenta como um caso relevante, principalmente, no momento em que assumem a gestão municipal as principais lideranças das organizações sociais do campo. Assim, o desafio é assumir na gestão pública a totalidade da pauta de reivindicação do movimento social como elemento de referência de uma nova estrutura societal.

\section{ECONOMIA SOLIDÁRIA COMO ESTRATÉGIA DE DESENVOLVIMENTO TERRITORIAL: O CASO DE IGARAPÉ- MIRI - PARÁ}

Situado na Mesorregião Nordeste do Pará, na Microrregião de Cametá, o município de Igarapé-Miri pertence ao (culturalmente chamado) Território do

Novos Cadernos NAEA, v. 16, n. 1, Suplemento, p. 43-67, jun. 2013 
Baixo Tocantins, distante em linha reta a $78 \mathrm{~km}$ da capital Belém. Limita-se ao Norte com o município de Abaetetuba, a Leste com o município de Moju, ao Sul com os municípios de Cametá e Moju e a Oeste com os municípios de Cametá e Limoeiro do Ajuru (IGARAPÉ-MIRI, 2004). Possui uma população de 58.023 habitantes, dos quais 26.209 (45,17\%) residem na zona urbana e 31.814 (54,83\%) na zona rural (BRASIL, 2010), e área territorial de 2.000,7 km² (IGARAPÉ-MIRI, 2004). Do ponto de vista econômico, Igarapé-Miri caracteriza-se, principalmente, pelo trabalho com agricultura e agroextrativismo, com ênfase para o cultivo e manejo do açaí e a pesca artesanal.

Não diferente da linha histórica de formação econômica do Brasil, Igarapé-Miri também explica seu perfil de socioeconomia com base em ciclos econômicos sistêmicos, ancorado em um modelo dicotômico de relação campo-cidade. Refletindo qualitativamente sobre esse município, Corrêa (2006) enfatiza que

Historicamente Igarapé-Miri experimentou processos de crescimento econômico que marcaram a estruturação e representação da organização social, política e cultural do município. Surgiu enquanto território já com a herança do desmatamento para comercialização da madeira, do comércio e regatões típicos da economia mercantil, entrou para a economia da cana-de-açúcar onde viveu o período áureo de sua economia, embora fadada aos desafios históricos da acumulação do capital a exemplo do desenvolvimento tecnológico. Marcado ainda pela cultura econômica do aviamento e pelas relações político-sociais de compadrio (CORRÊA, 2006, p. 01).

O exame dessa particular realidade confirma, na vivência de tais ciclos, um modelo de desenvolvimento visceralmente capitalista que se nutre de seculares estruturas de exploração (patrões versus empregados - patronato), insustentabilidade (prejuízos ambientais), acumulação e desequilíbrio social (competição, assalariamento, ricos versus pobres), entre outros indicadores. Transitando nesse conjunto de referências, o ciclo da cana-de-açúcar para produção de aguardente a partir de engenhos, em se tratando de IgarapéMiri, constitui um expoente exemplo do inviável e excludente paradigma de desenvolvimento capitalista aqui debatido.

O final da década de 1980, entretanto, simboliza um divisor de águas na formação histórica desse município. O estrangulamento do ciclo de monocultura da cana-de-açúcar e colapso da indústria de produção de aguardente, ao mesmo tempo em que produziu estagnação econômica (com todos os seus malefícios) provocou uma sensibilização comunitária sobre o sentido da cidadania, espírito de organização sociopolítica e unidade em torno de um projeto alternativo 
de sociedade, estratégia, enfim, protagonizada por sujeitos do campo, fundamentalmente (REIS, 2008).

A partir da segunda metade dessa mesma década, as conquistas referentes à Colônia de Pescadores (Z-15) e ao Sindicato dos Trabalhadores Rurais (STR), resultados de articulações e lutas de agricultores familiares e pescadores artesanais conscientemente influenciados por formações da igreja católica, indica um novo ciclo de debate político e construção do desenvolvimento local. O impulso desse processo de organização social agora mobiliza o surgimento de associações e cooperativas (REIS, 2008, p. 50) então formatadas para viabilizar as estruturas socioprodutivas criadas por aqueles atores. O pioneiro desses instrumentos fora batizado por seus sujeitos como Projeto Mutirão, uma espécie de Centro de Formação e Tecnologia Social em Desenvolvimento Sustentável com foco no associativismo/cooperativismo e na agricultura familiar. Gestado no início da década de 1990, o Projeto Mutirão ainda hoje cumpre uma importante função de "laboratório do campo", já tendo subsidiado a formação de diversos outros empreendimentos de natureza associativista e/ou cooperativista no município.

A aposta que nessa conjuntura se fez com a cultura do açaí como principal cadeia produtiva da economia familiar miriense, em essência, não representou o sepultamento de um estrangulado ciclo econômico e a gestação de outro monocultivo vegetal, mas, o rompimento com um ciclo histórico de promoção da exploração intensiva do trabalho para a incorporação de novas formas de organização do trabalho, com características de autonomia. Desta vez, as bases orientadoras do desenvolvimento são outras: (i) uma postura mais consciente e sustentável na exploração do meio ambiente; (ii) a inversão na prioridade de valores, da lógica capital-trabalho=capital-riqueza para homemtrabalho=trabalho-riqueza e (iii) o emponderamento/emancipação dos sujeitos na formação de um capital social, não citando outros elementos.

A denúncia reflexiva argumentada neste texto caracteriza a dinâmica de formação econômica do território em debate sob dois vieses: por um lado, enquanto fruto da omissão do Estado, natural promotor de políticas públicas, na indução do desenvolvimento local; e, por outro, como evolução do estágio de militância social que culmina (em função da primeira circunstância) com a obrigatoriedade imposta aos trabalhadores de fazer um "Estado paralelo" (ARAÚJO, 2011). O estudo desse cenário lembra a lição de Paulo Freire citada por Mance (2003), cujo conteúdo ensina que:

O exercício da cidadania por quem sofre qualquer das discriminações não é algo de que usufruam como direito pacífico e reconhecido. É um direito a ser alcançado e cuja conquista faz crescer a democracia [...]. É uma

Novos Cadernos NAEA, v. 16, n. 1, Suplemento, p. 43-67, jun. 2013 
construção que, jamais terminada, demanda briga por ela, engajamento, clareza política, coerência, decisão (FREIRE, 1993, p. 19 apud MANCE, 2003, p. 14).

Essa trajetória de movimento faz emergir no seio do capital social em formação um novo desafio de mobilização e organização social: a necessidade de incidir na conjuntura da gestão municipal para (re)dimensionar os rumos das políticas públicas de desenvolvimento e, de fato, promover um Estado presente. Nessa perspectiva, a segunda metade da década de 2000 inaugura um processo histórico ímpar em Igarapé-Miri. Algo semelhante ao que aconteceu na recente história da política governamental brasileira: a chegada de um ex-operário da construção naval ao governo ${ }^{6}$ do município. Até certo ponto, isso se confunde com a experiência nacional e representa um marco no processo de militância dos trabalhadores, porquanto indica o amadurecimento da consciência política coletiva, o fortalecimento e articulação dos instrumentos institucionais de resistência e a qualificação do projeto alternativo de desenvolvimento local nos quais esses sujeitos se inserem.

São as diretrizes, os objetivos e as ações sistematizados na militância social que desta vez devem subsidiar o (ou se tornarem componentes do) planejamento estratégico (e programa) de governo da gestão municipal. Constante da pauta de medidas estruturantes desse processo de planejamento, a reforma administrativa do município institui um novo formato para a política de desenvolvimento econômico. Oportunamente, a então Secretaria Municipal de Agricultura (SEMAGRI) torna-se Secretaria Municipal de Desenvolvimento Econômico e Trabalho (SEDET), com a prerrogativa estratégica de atuar, além do setor agrícola, nas políticas setoriais da pesca e aquicultura, indústria, comércio e serviços e economia solidária, conforme indica a Lei Municipal nº 4.989/2010 (IGARAPÉ-MIRI, 2010). Assim, a matriz de referências programáticas da nova gestão reconhece/estabelece:

a) Que ao lado do setor agropecuário há um conjunto de outras vocações socioeconômicas igualmente importantes para o desenvolvimento municipal;

b) Como estratégia o desafio de induzir o desenvolvimento com base na estruturação e no fortalecimento dessas múltiplas vocações;

\footnotetext{
${ }_{6}$ Depois de duas tentativas fracassadas, a terceira eleição de Roberto Pina Oliveira ao governo de Igarapé-Miri, agora com sucesso, simboliza não apenas a vitória de um projeto político (alternativo) de desenvolvimento produzido e alimentado pelos trabalhadores ao longo de três décadas, mas a efetiva chegada desses trabalhadores ao governo local (2009-2012), com a premissa de que é preciso (e possível) fazer como gestão pública municipal o que se fez e reivindicou enquanto movimento social.
}

Novos Cadernos NAEA, v. 16, n. 1, Suplemento, p. 43-67, jun. 2013 
b) Que a histórica relação dicotômica campo-cidade deve ser superada, entendendo-se que a política pública só se justifica a partir de seu caráter universalizante.

Enquanto eixo setorial de uma estrutura macro, a política municipal de economia solidária é qualificada como estratégia de desenvolvimento. Note-se que a plataforma ideológica fundamentada na territorialidade gestada pelos movimentos, agora representa um conceito-base da gestão pública municipal para formulação e/ou operacionalização das políticas públicas. O Departamento de Economia Solidária (DECOSOL/SEDET), criado nessa nova institucionalização, torna-se o instrumento operacional da política de Economia Solidária em Igarapé-Miri. Em suma, credencia-se como o primeiro aparelho público de fomento à outra economia no Território da Cidadania do Baixo Tocantins.

Como motor de desenvolvimento local sustentável, a política de economia solidária veste-se da missão de induzir, promover, fortalecer e/ou difundir práticas da outra economia (COUTO, 2009) em nível municipal - sob a perspectiva de território -, dando vazão a uma matriz alternativa de planejamento do desenvolvimento. Suas linhas estratégicas de atuação devem, entre outras premissas:

a) Favorecer o fortalecimento e verticalização de arranjos produtivos locais e cadeias produtivas sob a gestão de empreendimentos econômicos solidários (EES);

b) Promover capacitação, qualificação socioprofissional, assessoria e acompanhamento técnico com foco em demandas consolidadas/setorializadas e nas especificidades dos arranjos da economia solidária;

c) Fomentar a geração de trabalho e renda pela inclusão socioprodutiva e fomento às vocações econômicas locais, com prioridade ao trabalho coletivo;

d) Induzir à promoção de práticas de consumo local e/ou solidário e a articulação das cadeias produção e consumo no âmbito do município, tendo em vista à difusão cultural de uma lógica de fluxo econômico alternativo ao do capitalismo;

e) Subsidiar atividades de produção, consumo e prestação de serviços com políticas de finanças solidárias enquanto instrumentos de desenvolvimento local;

f) Difundir a realização de feiras circunstanciais e permanentes de economia solidária como experimentação concreta de outra economia possível;

g) Consolidar a estratégia municipal de economia solidária como política pública, em face da institucionalização de um marco legal para o seguimento.

Novos Cadernos NAEA, v. 16, n. 1, Suplemento, p. 43-67, jun. 2013 
Para se avaliar a aplicabilidade da agenda governamental de fomento a economia solidária (no contexto da política de desenvolvimento econômico) em estudo, buscou-se transcrever, no quadro abaixo, um resumido balanço analítico das intervenções implementadas por essa municipalidade no período de 2009 a 2011, com base no Relatório de Gestão da SEDET (IGARAPÉ-MIRI, 2011). Em contraste com as gestões anteriores, o quadro mostra avanços significativos no processo de desenvolvimento local, entretanto, evidencia limites substantivos a serem superados, quando da necessidade de promoção da economia solidária.

Quadro 1. Síntese analítica da Política de Economia Solidária e Desenvolvimento Econômico-Social da Gestão Municipal de Igarapé-Miri/PA (2009-2011).

\begin{tabular}{|c|c|c|}
\hline & Intervenção (2009-2011) & Limites a superar \\
\hline $\begin{array}{l}\text { Uma política de agricultura que } \\
\text { não considerava outros temas } \\
\text { referentes ao desenvolvimento }\end{array}$ & $\begin{array}{l}\text { Implantação da política de } \\
\text { desenvolvimento e social sob a } \\
\text { condução da SEDET }\end{array}$ & $\begin{array}{l}\text { Há incompreensão sobre o } \\
\text { novo desenho e carência de } \\
\text { infraestrutura e recursos }\end{array}$ \\
\hline $\begin{array}{l}\text { Nenhuma referência ao } \\
\text { tema da economia solidária } \\
\text { enquanto campo estratégico }\end{array}$ & $\begin{array}{l}\text { Inclusão da economia solidária } \\
\text { na política de desenvolvimento } \\
\text { econômico e social }\end{array}$ & $\begin{array}{l}\text { À economia solidária é dada } \\
\text { uma condição periférica na } \\
\text { estrutura administrativa }\end{array}$ \\
\hline $\begin{array}{l}\text { A prioridade dada à agricultura } \\
\text { excluía outros seguimentos } \\
\text { econômicos }\end{array}$ & $\begin{array}{l}\text { Incentivos para diferentes } \\
\text { seguimentos econômicos, } \\
\text { desta vez, tanto para rurais } \\
\text { como para urbanos }\end{array}$ & $\begin{array}{l}\text { As ações são ainda muito } \\
\text { pontuais, } \\
\text { consolidadas como políticas } \\
\text { governamentais }\end{array}$ \\
\hline $\begin{array}{l}\text { O conceito de cadeia } \\
\text { produtiva solidária não era } \\
\text { pensado no planejamento do } \\
\text { desenvolvimento }\end{array}$ & $\begin{array}{l}\text { A política de desenvolvimento } \\
\text { deve ter foco em cadeias } \\
\text { produtivas solidárias }\end{array}$ & $\begin{array}{l}\text { Não basta ter cadeias é preciso } \\
\text { integrá-las para compor } \\
\text { sistemas produtivos }\end{array}$ \\
\hline $\begin{array}{l}\text { Ausência de discussão } \\
\text { sobre segurança alimentar e } \\
\text { nutricional (SAN), enquanto } \\
\text { gestão. }\end{array}$ & $\begin{array}{l}\text { O fomento a segurança } \\
\text { alimentar/nutricional compõe } \\
\text { a pauta do desenvolvimento }\end{array}$ & $\begin{array}{l}\text { Deve-se avançar na } \\
\text { implantantação de um Sistema } \\
\text { Municipal de SAN. }\end{array}$ \\
\hline $\begin{array}{l}\text { Apenas os movimentos } \\
\text { sociais falavam sobre finanças } \\
\text { solidárias (pelo cooperativismo } \\
\text { de crédito) }\end{array}$ & $\begin{array}{l}\text { Inserção do tema na política } \\
\text { de ecosol com a criação de um } \\
\text { Banco Comunitário }\end{array}$ & $\begin{array}{l}\text { Apesar de criado, o suporte } \\
\text { dado ao Banco Comunitário é } \\
\text { (ainda) quase invisível. }\end{array}$ \\
\hline $\begin{array}{l}\text { Promover a comercialização } \\
\text { era tarefa apenas dos } \\
\text { empreendimentos de ecosol. }\end{array}$ & $\begin{array}{l}\text { O acesso a mercados (PAA, } \\
\text { PNAE, Feiras), por EES, } \\
\text { compõe a política municipal de } \\
\text { economia solidária. }\end{array}$ & $\begin{array}{l}\text { A qualificação, agregação de } \\
\text { valor e melhoria na logística } \\
\text { são grandes desafios aos EES }\end{array}$ \\
\hline $\begin{array}{l}\text { Formar e acompanhar EES } \\
\text { eram demandas exclusivas dos } \\
\text { movimentos sociais }\end{array}$ & $\begin{array}{l}\text { Promover e/ou fortalecer } \\
\text { EES tornam-se estratégias de } \\
\text { difusão de outra economia, pela } \\
\text { gestão local. }\end{array}$ & $\begin{array}{l}\text { Como política, a promoção } \\
\text { de EES carece de estruturas, } \\
\text { suporte técnico e recursos } \\
\text { financeiros. }\end{array}$ \\
\hline
\end{tabular}

Fonte: Relatório de Gestão SEDET (IGARAPÉ-MIRI, 2011). Elaborado pelos autores. 
Um julgamento possível acerca da leitura acima disposta sugere como notório o avanço na implantação, naquele território, de uma política de economia solidária como estratégia de desenvolvimento. Isso pode ser testemunhado pelas intervenções já produzidas. No entanto, avalia-se que as limitações diagnosticadas fragilizam esse embrião de política pública, obstaculizando sua consolidação. Portanto, o Quadro 1 é representativo enquanto síntese analítica. Dessa forma, reforça o conceito de continuum de transitoriedades, utilizado como referência explicativa sobre a experimentação da economia solidária neste estudo.

O Quadro 2 esboça uma síntese do processo de transição da economia solidária de movimento para política governamental no município de IgarapéMiri. Identificam-se três momentos históricos específicos e complementares da trajetória desse município.

Quadro 2. Síntese do processo de transição da Economia Solidária em IgarapéMiri

\begin{tabular}{|l|l|}
\hline Fase transitória 1: & $\begin{array}{l}\text { Economia Solidária como movimento: outra economia acontece pela } \\
\text { organização de trabalhadores (inicialmente rurais) no campo da produção } \\
\text { e do consumo. }\end{array}$ \\
\hline Análise-síntese 1: & $\begin{array}{l}\text { Neste momento nota-se significativa autonomia dos trabalhadores em } \\
\text { relação à condução do movimento de economia solidária. Essa realidade, } \\
\text { teoricamente, sinaliza a emergência de um projeto de sociedade para além } \\
\text { do capital, tendo os movimentos sociais como protagonistas e gestores. }\end{array}$ \\
\hline Fase transitória 2: & $\begin{array}{l}\text { As organizações representativas dos trabalhadores promovem ações } \\
\text { voltadas para o tema político e econômico. E, como fruto dessa } \\
\text { organização, chegam à gestão do município. }\end{array}$ \\
\hline Análise-síntese 2: & $\begin{array}{l}\text { Desta vez os trabalhadores é que governam. Tem-se agora uma conjuntura } \\
\text { que desafia os movimentos sociais, o que pode ser transcrito a partir de } \\
\text { algumas indagações: como implantar o projeto de economia solidária não } \\
\text { se tendo os poderes necessários em mãos (apenas o governo)? E, se os } \\
\text { militantes estão governo, quem continua a militância? }\end{array}$ \\
\hline Fase transitória 3: & $\begin{array}{l}\text { De movimento à política governamental: em tese acredita-se que as } \\
\text { diretrizes, os objetivos e as ações construídos na militância social agora } \\
\text { devem subsidiar a agenda de governo. }\end{array}$ \\
\hline Análise-síntese 3: & $\begin{array}{l}\text { Na contramão do que se esperava a falta de estruturas e recursos } \\
\text { obstaculizam a implantação da política de economia solidária. Por isso, } \\
\text { o formato (periférico) de tal política não é capaz de alterar radicalmente } \\
\text { as estruturas socioeconômicas vigentes. A isso converge certa inércia dos } \\
\text { movimentos sociais, que não conseguem incidir. }\end{array}$ \\
\hline
\end{tabular}

Fonte: Pesquisa de campo (2012). Elaboração dos autores

Os elementos de análise sistematizados no quadro acima guardam estreita relação com (ou encontram explicação em) diversos fundamentos teóricos sobre a construção da economia solidária no Brasil (BENINI et al. 2011; 2012), especialmente no que tange aos conceitos de experimentação e/ou transitoriedade sempre muito presentes na trajetória dessa outra economia. Dialogando com 
autores ocupados com o tema da economia solidária, em análise a transitoriedade na experimentação dessa outra economia no município de Igarapé-Miri, do ponto de vista de seus desafios/problemas, os três próximos parágrafos confirmam que, ao lado dos acúmulos construídos na trajetória da economia solidária por esse território, grandes desafios obstaculizam e/ou estrangulam a consolidação da economia solidária enquanto política de desenvolvimento.

Uma das razões históricas que explicam esse cenário diz respeito ao fato de que, embora a experimentação da economia solidária corresponda à aparição de fenômenos de organização de trabalhadores em diferentes campos profissionais, esses situados movimentos, a rigor, não têm expressado uma autônoma tomada de consciência pelos trabalhadores e sim uma fuga aos massacres do capitalismo (SINGER, 2002; NASCIMENTO, 2011).

Por outro lado, analisa-se que, no Brasil, a formação de governos ditos democráticos populares não tem se refletido em mudanças revolucionárias nas estruturas do Estado. O que significa que o capital continua "ditando as regras" tendo, portanto, poder político sobre o Estado. Há boas políticas e não falta planejamento, a questão é: pra quem se tem planejado e dirigido as políticas? Parece que não tem sido para democratizar a política, a economia, o Estado. Isso se cristaliza à medida que organizações de trabalhadores tornam-se governo, quando há uma crise de identidade, de projeto, além da natural fragilização de seus arranjos sociais, em função do comprometimento de lideranças e agentes com um ou outro projeto (DAGNINO, 2011; GENNARI, 2011).

Em suma, aceitando-se que o Estado não está a serviço do conjunto da sociedade e sim do capital, mesmo governos populares têm dificuldades para implantar políticas públicas de Economia Solidária priorizadas e arquitetadas para contrapor as estruturas macroeconômicas do capitalismo, sendo a este uma alternativa viável. Os trabalhadores, quando se organizam, o fazem de modo segmentado (do ponto de vista macro), fragilizando seu poder de intervenção. E, se buscam intervir na agenda Estatal, são fortemente barrados (DAGNINO, 2011; DIAS; SERAFIM, 2011).

Considerando as reflexões tecidas neste trabalho sobre a trajetória da economia solidária no Território da Cidadania do Baixo Tocantins, e o consequente estudo de caso relativo à experiência de Igarapé-Miri, o esquema a seguir formatado sugere um conjunto de elementos, na forma de matriz/fluxo de conteúdos, como proposição para o fortalecimento da economia solidária enquanto política pública no campo do desenvolvimento local-territorial. 
Figura 2. Proposição esquemática de uma Política Pública de Economia Solidária como Estratégia de Desenvolvimento Local-Territorial.

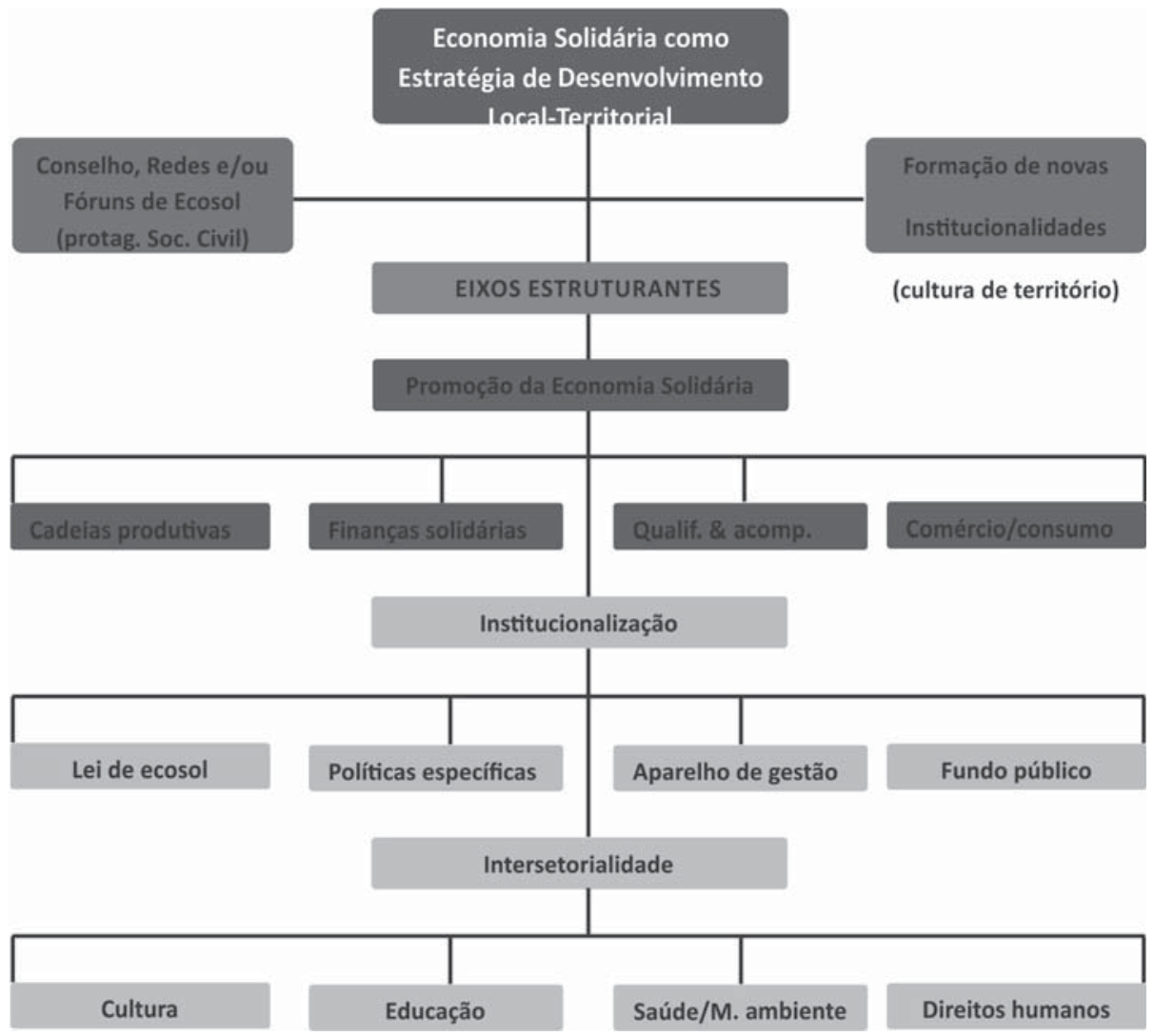

Fonte: Pesquisa de campo (2012). Elaboração dos autores.

A lógica na qual se fundamenta o esquema acima indica que a consolidação da economia solidária como política pública municipal e estratégia de desenvolvimento territorial passa necessariamente pela execução de pelo menos três processos simultâneos e integrados. O primeiro desses processos, aqui chamado de promoção da economia solidária, refere-se à necessidade de difusão de outra economia possível, o que tem haver com a afirmação programática da economia solidária enquanto ação política. Para construir esse cenário acreditase que o trabalho com cadeias produtivas seja oportuno, por possibilitar o alcance de um vasto número de seguimentos socioprodutivos. Tais cadeias devem ser alimentadas pelas chamadas finanças solidárias (já que o sistema financeiro convencional não compreende satisfatoriamente o universo da economia solidária) e por instrumentos de qualificação e acompanhamento. O resultado da combinação entre a opção pelo conceito de cadeia produtiva e Novos Cadernos NAEA, v. 16, n. 1, Suplemento, p. 43-67, jun. 2013 
seu fortalecimento desencadeará um conjunto de arranjos de comercialização e consumo, viabilizando o sistema socioeconômico ora proposto.

O segundo processo, relativo à institucionalização da política de economia solidária, retoma (e sintetiza) o debate sobre a transição da economia solidária de movimento para política pública. Esse desenho pressupõe que a economia solidária seja incorporada na agenda do Estado enquanto prioridade estratégica, qualificando-se no aparelho estatal como dever deste e direito da sociedade. No entanto, não se deve perder de vista o caráter autônomo e autogestionário das organizações representativas do movimento de economia solidária, porque assim poderá ser mantida sua independência política e econômica, uma vez que a ação governamental deve assumir seu papel de fomento e apoio e não funções que possam indicar tutela das experiências advindas da sociedade civil.

O desafio da intersetorialidade entre a política de economia solidária e outras afins constitui o terceiro processo apontado. Do ponto de vista do planejamento trata-se de conceber a transversalidade inerente ao organismo da economia solidária como característica propícia à indução de uma plataforma de desenvolvimento. A condição de ser transversal favorece o desempenho da economia solidária em uma matriz intersetorial de atuação.

Note-se, ainda, que a posição ocupada no esquema pela categoria Conselho, Redes e/ou Fóruns de economia solidária, estrategicamente, quer dar evidência a um elemento conceitual aqui considerado essencial para a promoção e o fortalecimento da economia solidária: o protagonismo da sociedade civil, daí porque tal elemento se encontra numa posição de destaque na matriz ora analisada. Entende-se que, além de indicar a necessidade de controle social pela sociedade civil, a categoria em questão sugere que os atores/movimentos sociais não podem figurar apenas como beneficiários da política pública de ecosol, antes devem participar do protagonismo na formulação, execução e controle dessa política, obviamente dela se usufruindo enquanto direito. Para tanto, torna-se oportuno pensar na construção de novos arranjos de desenvolvimento, em face do que a fértil metodologia das redes solidárias parece um caminho inteligente.

Nesse sentido, o formato de política pública em análise somente será possível com a constituição de novas institucionalidades no território. Percebese que a viabilidade do desenho proposto está sujeita (também) a presença de habilidades sociais (FLIGSTEIN, 2007), enquanto indutoras da formação desse lugar-comum. Tendo-se em conta que a construção de um território é resultado (sobretudo) de opções humanas, o conceito de habilidade social, originário do "interacionismo simbólico" e definido "como a habilidade de induzir a cooperação dos outros" (FLIGSTEIN, 2007), torna-se um importante fundamento para a

Novos Cadernos NAEA, v. 16, n. 1, Suplemento, p. 43-67, jun. 2013 
ação política dos sujeitos territoriais, uma vez que "[...] a vida social gira em torno de obter uma ação coletiva, e isso requer que os participantes dessa ação sejam induzidos a cooperar" (FLIGSTEIN, 2007, p. 62).

\section{CONSIDERAÇÕES FINAIS}

As transformações sócio-espaciais, políticas e econômicas experimentadas pelo Território da Cidadania do Baixo Tocantins, de modo especial ao longo das últimas três décadas, são atual expressão de sua multidimensionalidade. Conforme defendido neste trabalho, o Baixo Tocantins constitui-se como um território marcado por processos autônomos e contradições, em cujo tecido socioeconômico conflitam padrões de desenvolvimento antagônicos, em última análise, representativos do modelo de sociedade historicamente em disputa na região.

Verifica-se que o padrão de desenvolvimento pautado em grandes projetos, bastante difundido nesse território, essencialmente responde aos interesses de mobilidade do capital e a sua doutrina. O cumprimento dessa agenda demanda subordinação e/ou alienação do trabalho ao capital, tendo em vista a conquista de lucro a qualquer preço para a concentração de riqueza. Paradoxalmente, um modo de vida pautado em novas ruralidades e territorialidades têm convivido e resistido ao padrão capitalista. Esse desenvolvimento notabiliza-se na agricultura familiar, no extrativismo e na pesca; no dinamismo das comunidades tradicionais e dos empreendimentos econômicos rurais e urbanos. Fala-se de uma dinâmica territorial com uma matriz configurada por índices favoráveis de valorização do trabalho, distribuição de riqueza e sustentabilidade ambiental. Uma territorialidade propensa ao uso coletivo da propriedade e dos meios de produção por se alimentar de processos organizativos protagonizados por trabalhadores livremente associados. Eis o movimento que, em sentido histórico, constitui a economia solidária na região.

Nessa perspectiva, a trajetória de Igarapé-Miri na experimentação da economia solidária mostra-se representativa da territorialidade do Baixo Tocantins. Enquanto estudo de caso, este texto possibilita compreender tal trajetória como um continuum de transitoriedades: que se inicia nas vivências associativas de comunidades de base; logo, amadurece com a atuação dos empreendimentos econômicos solidários e entidades de apoio; e, agora, caminha para uma possível consolidação no âmbito das políticas públicas. 
Entretanto, uma investigação mais rigorosa desse processo revela que a economia solidária em Igarapé-Miri e na região ainda não configura stricto sensu uma estratégia de desenvolvimento, em função de múltiplos limites e estrangulamentos, sobretudo sua condição experimental. Ao que parece, a economia solidária tem sido construída mais como instrumento ideológico de resistência ao capital e mesmo como uma paliativa oposição à desestruturação do mundo do trabalho. Sua definição como estratégica política de desenvolvimento territorial ainda aguarda prioridade nas agendas dos sujeitos institucionais, de cunho governamental, e dos sujeitos das organizações do movimento social.

\section{REFERÊNCIAS}

ABRAMOVAY, R. O capital social dos territórios: repensando o desenvolvimento territorial. Economia Aplicada, v. 4, n. 2, abr./jun. 2000.

ALMEIDA, J. Da ideologia do progresso à ideia de desenvolvimento (rural) sustentável. Revista Educação Agrícola Superior, Brasília, v. 15, n. Especial, p. 51-85, 1997.

ARAÚJO, I. F. (Org.). Educação do campo, desenvolvimento sustentável e sociedade. Abaetetuba: WGW Gráfica \& Editora, 2011. p. 17-45.

ARAÚJO, I. F; SOUZA, A. L. de. Economia solidária como estratégia de desenvolvimento local: de movimento à política pública - refl exões com base na trajetória do município de Igarapé-Miri (PA). Igarapé-Miri. In: SEMANA ACADÊMICA DO INSTITUTO DE CIÊNCIAS SOCIAIS APLICADAS - ICSA, 2012. Belém. Trabalho apresentado... Belém: Universidade Federal do Pará, 2012.

ARAÚJO, J. R. B. Cooperativismo. Curso de Formação de Gestores de Cooperativismo. Belém: ADA/Amazônia, 2003. Inédito.

BENINI É. et al. Gestão pública e sociedade: fundamentos e políticas públicas de Economia Solidária. 1. ed. São Paulo: Outras Expressões, 2011. v. 1.

BENINI É. et al. Gestão pública e sociedade: fundamentos e políticas públicas de Economia Solidária. 1. ed. São Paulo: Outras Expressões, 2012. v. 2.

BRASIL. Instituto Brasileiro de Geografia e Estatística. Censo agropecuário 2006: resultados preliminares. Rio de Janeiro: IBGE, 2006. 146 p.

Ministério do Desenvolvimento Agrário. Secretaria de Desenvolvimento

Territorial. Plano Territorial de Desenvolvimento Rural Sustentável do Baixo Tocantins (PTDRS). Brasília: MDA/SDT, 2011. Disponível em: www.mda.gov.br. 
CORREAA, E. de J. A. O arranjo produtivo local dos construtores de barcos artesanais: fundamentos para o desenvolvimento endógeno do Baixo Tocantins (PA). 2010. Dissertação (Mestrado em Planejamento do Desenvolvimento) - Núcleo de Altos Estudos Amazônicos, Universidade Federal do Pará, Belém, 2010.

Construindo o projeto alternativo de desenvolvimento local. $\mathrm{O}$ desenvolvimento que temos e o desenvolvimento que queremos: por um Igarapé-Miri feito em Mutirão. In: ENCONTRO MUNICIPAL DE LIDERANÇAS SOCIAIS. Texto de Apoio: Igarapé-Miri, 2006. Inédito.

COUTO, R. do. (Org.). Plano Municipal de Desenvolvimento Econômico Sustentável de Igarapé-Miri, 2009-2012. Igarapé-Miri: Prefeitura Municipal/Secretaria de Desenvolvimento, 2009.

DAGNINO, R. Gestão social e gestão pública: interfaces, delimitações e uma proposta. In: BENINI, É. et al. Gestão pública e sociedade: fundamentose políticas da Economia Solidária. 1. ed. São Paulo: Outras Expressões, 2011. v.1. p. 339-406

DIAS, R.; SERAFIM, M. P. Conceitos e ferramentas para a análise de Política Pública. In: BENINI, Édi et al. Gestão pública e sociedade: fundamentos e políticas da Economia Solidária. 1. ed. São Paulo: Outras Expressões, 2011. v. 1. p. 305-337.

FLIGSTEIN, N.. Habilidade social e a teoria dos campos. RAE, São Paulo, v. 47, n. 2, abr./jun. 2007.

GAIGER, L. I. (Org.). Sentidos e experiências da economia solidária no Brasil. Porto Alegre: Editora da UFRGS, 2004.

. A economia solidária diante do modo de produção capitalista. Caderno $\mathbf{C R H}$, Salvador: UFBA, n. 39, p, 181-211, 2003.

GENNARI, A. M. Globalização, Estado, neoliberalismo e desigualdade social no Brasil. In: BENINI, Édi et al. Gestão pública e sociedade: fundamentos e políticas da Economia Solidária. 1. ed. São Paulo: Outras Expressões, 2011. v. 1. p. 21-46.

IGARAPÉ-MIRI. Prefeitura Municipal de Igarapé-Miri. Secretaria de Desenvolvimento Econômico e Trabalho. Relatório de Gestão 2011. Igarapé-Miri: Prefeitura Municipal, 2011.

- Prefeitura Municipal de Igarapé-Miri. Gabinete do Prefeito. Lei Municipal $\mathbf{n}^{\mathbf{o}}$ 4.989/2010, de 25 de março de 2010. Igarapé-Miri: Prefeitura Municipal, 2010.

Prefeitura Municipal de Igarapé-Miri. Projeto GESPAN - Gestão Participativa de Recursos Naturais. Informações básicas sobre o município de Igarapé-Miri, Pará: uma contribuição para o seu planejamento. Igarapé-Miri: Prefeitura Municipal, 2004.

Novos Cadernos NAEA, v. 16, n. 1, Suplemento, p. 43-67, jun. 2013 
MANCE, E. A. (Org.). Como organizar redes solidárias. Rio de Janeiro: DP\&A; Fase; IFiL, 2003.

NASCIMENTO, C. A autogestão e o novo cooperativismo. In: BENINI, É. et al. Gestão pública e sociedade: fundamentos e políticas da Economia Solidária. 1. ed. São Paulo: Outras Expressões, 2011. v. 1. p. 91-99.

PERICO, R. E.; RIBERO, M. P. Ruralidade, territorialidade e desenvolvimento sustentável: visão do território na América Latina e no Caribe. Brasília, DF: IICA, 2005.

PERICO, R. E. Identidade e território no Brasil. Brasília, DF: IICA, 2009.

REIS, A. A. dos. Estratégias de desenvolvimento local sustentável da pequena produção familiar na várzea do município de Igarapé-Miri (PA). 2008. Dissertação (Mestrado em Planejamento do Desenvolvimento) - Núcleo de Altos Estudos Amazônicos, Universidade Federal do Pará, Belém, 2008.

SINGER, P. Introdução à Economia Solidária. 1. ed. 3. reimp. São Paulo: Perseu Abramo, 2002.

. Economia solidária: um modo de produção e distribuição. In SINGER, P.;

SOUZA, A. (Orgs.) A Economia Solidária no Brasil: a autogestão como resposta ao desemprego. São Paulo: Contexto, 2000.

SOUSA, R. V. Modalidade do crédito, organizações coletivas e reprodução camponesa na história de Cametá. 2000. 222 f. Dissertação (Mestrado em Planejamento do Desenvolvimento) - Núcleo de Altos Estudos Amazônicos, Universidade Federal do Pará, Belém, 2000.

SOUZA, A. L. de. Política pública de economia solidária e desenvolvimento territorial. Boletim Mercado de Trabalho, Brasília: IPEA, n. 52, p. 63-70, 2012.

. Trabalho e desenvolvimento territorial na Amazônia oriental: a experiência da rede de desenvolvimento rural do baixo Tocantins (PA). 2011. 220f. Tese (Doutorado em Desenvolvimento Rural) - Faculdade de Ciência Econômica, Universidade Federal do Rio Grande do Sul, Porto Alegre, 2011.

SOUZA, A. L. de; FILIPPI, E. E. Controvérsias do desenvolvimento territorial: alguns aspectos da ruralidade na Amazônia brasileira. Revista Conexões, Belém, v. 1, n.1, p. 91-116, 2008.

WANDERLEY, M. de N. B. O mundo rural como um espaço de vida: reflexões sobre a propriedade da terra, agricultura familiar e ruralidade. Porto Alegre: UFRGS, 2009.

Texto submetido à Revista em 19.09.2012

Aceito para publicação em 15.03.2013

Novos Cadernos NAEA, v. 16, n. 1, Suplemento, p. 43-67, jun. 2013 
